\title{
O QUE SOBROU: MATERIALIDADE E COLONIALISMO NUMA COLEÇÃO DE IMAGENS EM MOVIMENTO
}

\author{
Sofia Sampaio ${ }^{1}$ \\ ${ }^{1}$ Centro em Rede de Investigação em Antropologia (CRIA), Instituto \\ Universitário de Lisboa (ISCTE-IUL), Lisboa, Portugal
}

Au moment de sa fondation, en 1946, et pour plusieurs années encore, la Cinemateca Nacional du Portugal n'abritait pas de collection dite "coloniale". On y trouvera bientôt, comme dans presque toutes les collections portugaises, des copies de Chaimite, la saga coloniale de Jorge Brum (1953); quelques documentaires sur Luanda ou Lourenço Marques (l'actuel Maputo); des images de paysages et des bêtes dans les réserves de chasse. Et c'était tout!

(Pimentel 2002:22)

A relação entre imagens e colonialismo tem sido objeto de numerosos estudos, sobretudo no que diz respeito às imagens fixas. Fotografias, postais, cartazes e selos têm sido olhados e interpretados sob este ângulo de forma profícua, envolvendo áreas disciplinares tão distintas como os estudos culturais e visuais, a história, a antropologia, a museologia, entre outras, num clima de intenso diálogo interdisciplinar. ${ }^{1}$ No caso da fotografia, tem-se verificado uma evolução de tendências que nela viam um instrumento do poder colonial tout court para o reconhecimento de uma maior complexidade e ambiguidade na relação entre fotografia e império (Ryan 2014) - ou, para adotar uma expressão mais útil, entre fotografia e as várias "culturas coloniais", concebidas como descontínuas e incertas. ${ }^{2}$

O abrandamento, nos estudos visuais, da influência foucauldiana, que fazia alinhar as tecnologias visuais (senão mesmo a própria visualidade) com os regimes de poder/saber de uma forma por vezes determinista (Mitchell 2002), ${ }^{3}$ tem possibilitado o aparecimento de quadros conceptuais $^{4}$ não menos cientes deste tipo de cumplicidades, mas mais atentos às particularidades históricas, formais e materiais em que essas cumplicidades se desenvolveram. ${ }^{5}$ Para tal contribuiu também uma série de renovações teóricas e metodológicas, tais como: o interesse por arquivos visuais (nomeadamente, fotográficos) por parte de disciplinas pouco habituais ou deles 
temporariamente arredadas, como é o caso da antropologia (Bouquet 2001); o interesse por imagens não oficiais (fotografia amadora, vernácula, ou até "nativa"); e o interesse pela materialidade das imagens, no que tem sido já apelidado de "viragem materialista" nos estudos de fotografia, realizada, em boa medida, pela mão ou sob inspiração da antropologia (Edwards \& Hart 2004a; Edwards 2012). Todos estes fatores têm vindo a impulsionar o estudo das "imagens coloniais" - entendidas aqui de uma forma genérica, como imagens produzidas em ou sobre contextos dominados por regimes coloniais (formais ou informais), com ou sem a intervenção direta desses regimes. ${ }^{6}$

É o último destes aspetos - a "viragem materialista" - que me interessa explorar neste artigo. A viragem materialista nos estudos de fotografia operou importantes deslocamentos conceptuais e epistemológicos. Com o reconhecimento da sua condição de objeto tridimensional (Edwards 2002; Edwards \& Hart 2004a), a fotografia deixou de ser vista apenas como imagem-conteúdo. As suas duas "facetas" - de imagem e de objeto - passaram a ter igual peso nas análises dos usos e das práticas a que a fotografia se tem vindo a prestar (cf. Porto 2004:113). Assim, se antes se confinavam à esfera do discurso e da representação, os usos e os significados da fotografia são agora também procurados na circulação das diferentes "formas presentacionais" (Edwards \& Hart 2004a:2), bem como nas agencialidades diretas ou mediadas que as fotografias vão adotando e assumindo ao longo das suas "trajetórias materiais" (Edwards \& Hart 2004a:5), "biografias culturais" (Kopytoff 1986) e "histórias sociais" (Appadurai 1986:34).

Ao contrário das imagens fixas (com destaque para a fotografia), as imagens em movimento "coloniais" permanecem, em larga medida, por investigar.7 Por "imagens em movimento" refiro-me às imagens produzidas pelo dispositivo cinematográfico que, ao dotar a fotografia de movimento, ritmo e duração, inaugurou um novo meio cultural e artístico de mimetização do real que depressa conquistou, por via do entretenimento, um vasto público. Se a fotografia (objeto e prática) ${ }^{8}$ tomou o nome do processo fotoquímico que lhe dá forma (do grego, "escrita pela luz"), o cinema circula sob a designação de "filme" ou "fita" - o suporte material em que a imagem se imprimiu - ainda que essas designações se refiram, vulgarmente, ao conjunto de imagensconteúdo mostradas numa sala de projeção. Ou seja, ver um filme, uma experiência cultural complexa, não é olhar para a película que suporta as imagens fotográficas, fotograma a fotograma, mas sim ver o fluxo ininterrupto de imagens que, através de um foco de luz devidamente direcionado, permite vê-las como uma narrativa, um quadro ou uma sequência de quadros em movimento - animados, "vivos". ${ }^{9}$ Enquanto a fotografia está, por definição, associada a uma presença física, o filme precisa passar por um processo de 
transformação, a projeção, para adquirir presença (Edwards \& Hart 2004a:9). Trata-se necessariamente de uma presença fugaz, espectral, que lhe confere um cariz de intangibilidade. E, no entanto, sem o suporte material, as imagens em movimento simplesmente não existiriam. ${ }^{10}$

Serve esta breve digressão para posicionar as imagens em movimento não só em relação à fotografia (um fato que trato como teoricamente consequente), como também em relação às questões da materialidade. As imagens em movimento têm sido objeto de estudos que tendem a focar-se nos filmes, entendidos enquanto "obras" e "textos", o que favorece a que os aspetos materiais e extrafílmicos do cinema (quando considerados) se vejam reduzidos a dados contextuais dispersos com um valor interpretativo impressionista ou residual. Também os estudos nacionais dedicados ao filme colonial seguem uma via textual, continuando a valer-se de conceitos como "representação" e "imaginário" para reafirmar, de forma explícita ou implícita, uma concepção essencialmente instrumentalista das imagens em movimento que as reduz a expressões da propaganda (colonial ou anticolonial, conforme o caso). ${ }^{11}$

O objetivo principal deste artigo é argumentar que, tal como no caso da fotografia, a constatação do caráter material das imagens em movimento, bem como a integração, na pesquisa, das implicações teóricas daí decorrentes produzem avanços significativos neste campo de estudos, tornando mais aparentes e apreensíveis as complexidades que assistiram (e assistem) à relação entre imagens e colonialismo. A minha proposta conflui, ainda que por outras vias, com o trabalho da "nova história do cinema" (Elsaesser 2001) e, mais recentemente, da "arqueologia dos media" (Elsaesser 2016), que analisam o cinema de uma forma mais abrangente e integrada - como uma cultura, um evento e uma experiência social - sublinhando a necessidade de fazer acompanhar o estudo empírico de objetos fílmicos e extrafílmicos de um esforço permanente de (re)teorização. De modo semelhante, tomando como caso de estudo a coleção de filmes coloniais da Cinemateca Portuguesa-Museu do Cinema, o artigo pretende demonstrar que a adoção de um ponto de vista materialista para analisar estas imagens confronta-nos com os limites, as imprecisões e as aporias que minam o campo, sugerindo caminhos de investigação certamente mais longos e demorados, mas também mais produtivos e estimulantes.

A principal inspiração da presente proposta materialista procede, porém, da antropologia, que tem desenvolvido um trabalho particularmente inovador e consistente quer sobre a fotografia, quer sobre os arquivos coloniais. E não é por acaso que o tem feito, já que a história da antropologia se mistura com a destes dispositivos de poder e conhecimento. Com efeito, o papel que as práticas coletoras, museológicas e coloniais tiveram na formação disciplinar 
da antropologia e da etnologia tem sido amplamente estudado, nomeadamente no contexto francófono, em que uma antropologia positivista e "de resgate" procedeu à tarefa de recolher objetos por considerá-los vestígios e prova de modos de vida em extinção, tendo resultado na criação, ao longo do século XX, de vários museus etnológicos e etnográficos (Dias 1991, 2014, 2015; Sherman 2004).

A fotografia e o cinema acompanhavam, com frequência, o trabalho coletor nas colônias não só para testemunhar a "facticidade" dos objetos, como também para registrar os seus contextos e usos originais e "autênticos". Objetos e imagens eram então transportados do campo para o museu, num trânsito que ocorria (sobretudo, mas não exclusivamente) das colônias para a metrópole. Os filmes valiam pelo seu conteúdo informativo, isto é, como suplemento ou complemento dos objetos do museu (Porto 2004:115), pelo que eram anexados, juntamente com outros documentos, à ficha que identificava cada objeto (Dias 2014:195; Dias 2015:15; Porto 2001:43). Constituíam também um precioso recurso na organização de exposições (Dias 2014:195-196). Ainda que secundária, a existência material dos filmes não era completamente ignorada, já que dela dependia a integridade dos registros e, consequentemente, o próprio sucesso das missões. À chegada, tal como os restantes objetos, os filmes eram verificados, com vista a determinar o seu estado físico e a eventual necessidade de uma intervenção (Dias 2015:13).

Num museu do cinema, o enfoque é substancialmente diferente: aos filmes é reconhecido um valor documental (para muitos, a raison d'être do arquivo), mas é pela sua materialidade, como objetos a conservar e a preservar, que eles são fundamentalmente encarados. Muitos dos filmes do Arquivo Nacional das Imagens em Movimento (ANIM) da Cinemateca Portuguesa-Museu do Cinema - alguns dos quais atualmente reunidos na sua "coleção colonial"12 - tiveram origem em missões científicas e etnográficas similares, tendo acompanhado outros objetos no seu trânsito atlântico. ${ }^{13}$ Reposicionar estas imagens enquanto objetos de um arquivo permite-nos apreciar a sua condição material itinerante (e, eventualmente, de mercadoria), isto é, a sua participação numa circulação sujeita a atrasos, acelerações, bloqueios e desvios (Appadurai 1986:22-29), que terá deixado marcas nos próprios objetos, e da qual poderão ainda existir registros. Permite-nos pensar (e, nalguns casos, reconstituir) as "trajetórias materiais" dos filmes através de uma "perspectiva circulatória" (Dias 2015:12), ${ }^{14}$ que os concebe como parte integrante dos trânsitos entre "centros" e "periferias", lugares, regiões, nações e impérios, que deram forma e corpo ao próprio empreendimento colonial. 
Por fim, o exercício de confrontação com a materialidade da "coleção colonial" do ANIM, através de um escrutínio etnográfico que toma o arquivo como "campo" e objeto de estudo (Cunha 2004, 2005; Frehse 2005; Stoler 2009; Sampaio 2015), coloca-nos perante questões fundamentais para a compreensão das relações entre os tempos coloniais (o ontem arquivado) e os tempos pós-coloniais (o arquivo hoje), tais como: o caráter construído e essencialmente indefinido da coleção; o valor etnográfico e heurístico do conceito de fragmento, que emerge do próprio arquivo; os novos usos e significados a que a circulação dos filmes (quer enquanto parte de uma "coleção", quer de forma isolada) se veem agora associados.

Visitar um arquivo de imagens em movimento é entrar em contato, de forma mais ou menos próxima, com a materialidade das imagens. Foi essa a minha experiência quando, em Março de $2012,{ }^{15}$ no âmbito de uma outra pesquisa, passei a deslocar-me ao ANIM com regularidade, a fim de visionar um rol de imagens que só aí podiam ser visionadas. Este arquivo ocupa, desde 1996, instalações permanentes numa zona rural localizada ao Norte da cidade de Lisboa. Durante mais de um ano, numa base regular, e de forma mais espaçada nos anos seguintes, fiz a viagem de 30 minutos que liga o Campo Grande, no centro de Lisboa, ao ANIM. Fretado pela Cinemateca para o transporte dos seus funcionários, o autocarro do ANIM parte às 8h30 da manhã, regressando apenas ao final da tarde. Como escrevi alhures, para além de produzir uma ruptura espacial semelhante à vivenciada pelo antropólogo na sua saída de campo, a deslocação ao arquivo acabou por acarretar uma "deslocação epistemológica" que orientou a pesquisa para novas direções (Sampaio 2015:835, 837).

A imersão no arquivo tornou-me ciente dos seus meandros físicos e materiais, das suas condições de operacionalidade e limitações. Se, por um lado, o acesso aos filmes foi sempre feito de forma indireta e condicionada (são os funcionários que realizam a pesquisa no catálogo, produzem a lista de cópias visionáveis e transportam os materiais para a sala de visionamentos), por outro lado, a permanência no edifício e o conhecimento prático dos umbrais que me era permitido (ou não) transpor fizeram-me intuir a organização dos espaços e as funções que estes acolhiam. Posteriormente, em visitas abertas ao público, obtive acesso a depósitos de conservação, laboratórios de preservação e outros gabinetes de trabalho.

A estes espaços e tarefas passei também a associar as imagens que visionava. As listas iniciais deram origem a outras listas, frequentemente sugeridas pelas imagens que ia encontrando, ao acaso, nos cassetes de VHS que traziam os filmes por mim requisitados. As imagens procuradas viram-se, assim, complementadas e confrontadas pelas imagens achadas. 
A metáfora do arquivo como um "campo" foi-se tornando progressivamente mais palpável, quer sob a forma de "um campo imaginário de interlocuções com os autores e personagens que integram a documentação" (Frehse 2005:132) - neste caso, os filmes - quer sob a forma de um campo de relações e lógicas que refletem as condições de produção do próprio arquivo (Cunha 2004; Castro 2005). Estes dois entendimentos do "arquivo enquanto campo" subjazem à minha análise da "coleção colonial" da Cinemateca, que passo a desenvolver.

\section{Uma coleção}

A coleção colonial da Cinemateca Portuguesa-Museu do Cinema aparece pela primeira vez nomeada num artigo publicado por Joana Pimentel (2002), pesquisadora, prospetora e conservadora da Cinemateca. ${ }^{16}$ A autora faz remontar as origens desta coleção a 1982, quando a Cinemateca recebeu a produção fílmica da Agência Geral das Colónias/ do Ultramar (AGC/AGU, 1924-1974), à qual se juntariam, dois anos mais tarde, filmes provindos dos Laboratórios da Tóbis Portuguesa. ${ }^{17}$ No entanto, só em 1996, quando se reuniram as condições para a conservação, o restauro e o visionamento dos filmes, e com a identificação e a inventariação dos materiais de diversas proveniências, é que começou a ser possível falar numa "coleção colonial" propriamente dita (Pimentel 2002:22). ${ }^{18}$

Lamentando a ausência (que aparentemente se mantém) de uma filmografia colonial, o artigo de Pimentel fornece-nos importantes elementos sobre esta coleção, constituída, na sua maior parte, por documentários. Falamos de filmes que registram as missões cinematográficas às colônias, as feiras e as exposições coloniais que decorriam em Portugal e no estrangeiro, e algumas das excursões organizadas às colônias - tal como o filme do cruzeiro de estudantes ao ultramar, no Verão de 1935. Ou seja, falamos sobretudo de imagens encomendadas para fins de propaganda nacional e internacional que circularam, sob diversas formas, em exposições, feiras, conferências e cinemas comerciais (nestes últimos, integrando as atualidades filmadas, que passavam antes do longa-metragem). A presença da ficção é residual. ${ }^{19} \mathrm{O}$ artigo destaca ainda o filme Cultura de Cacau, de 1908, considerado o primeiro filme colonial português, do qual sobrevivem apenas alguns fotogramas, bem como o filme Angola - Exposição Provincial, Agrícola, Industrial e Pecuária, de 1923, cujos 224 metros representam as imagens em movimento mais antigas do "fundo colonial" da Cinemateca (Pimentel 2002:24). 
O que mais sobressai neste relato é o caráter fragmentário da coleção, já que muitas das obras estão incompletas e outras, sobre as quais existem documentos escritos, nunca foram encontradas. A especialização dos arquivos, que veio ditar a separação entre documentos escritos e visuais, mesmo quando pertencentes a uma mesma remessa, é outro fator de fragmentação. ${ }^{20} \mathrm{O}$ caráter aberto da coleção é igualmente evidente: algumas obras têm vindo a aparecer, por vezes inesperadamente, como é o caso de um filme do final dos anos 20 que só veio a ser depositado no arquivo 70 anos depois (Pimentel 2002:27), e a possibilidade de outros materiais poderem surgir, ainda que cada vez mais remota, não pode ser inteiramente descartada. ${ }^{21}$

Não obstante, nem o caráter fragmentário, nem o caráter aberto do arquivo colocam em causa a ideia de "coleção". Como vários autores têm sublinhado (Stewart 1984; Edwards \& Hart 2004b; Sassoon 2004), o que define uma coleção são os princípios que ditam a sua organização e não os objetos que a constituem. A criação de coleções pelos diversos arquivos e museus depende de decisões sobre o que é "coletável", o que deve ser incluído ou excluído, o que deve ser guardado mas não necessariamente catalogado, e o que deve ser simplesmente deitado fora (Brown \& Davis-Brown 1998:23). São vários os fatores que determinam a aplicação destes princípios - desde as práticas arquivísticas às políticas culturais que se fazem sentir dentro e fora das instituições.

O fato de a "coleção colonial" da Cinemateca se desenvolver no contexto de um arquivo-museu nacional comprometido em receber, para efeitos de conservação e preservação e como parte de um serviço público, a totalidade da produção fílmica nacional que lhe chega às mãos confere-lhe características particulares. ${ }^{22}$ A "coleção colonial" não é o resultado de uma intencionalidade definida a priori (por exemplo, no nível da prospecção de materiais). Ela também não designa uma entidade à parte, reconhecida enquanto tal durante as diferentes fases do trabalho arquivístico e merecedora de cuidado especial. O termo não é usado na base de dados do ANIM, ${ }^{23}$ nem remete para um espaço físico à parte (por exemplo, um depósito ou uma prateleira). Os filmes que a compõem estão sujeitos aos mesmos critérios historicistas, estéticos e patrimoniais que, sob influência da história do cinema e da história da arte, têm estado na base da formação deste arquivo (Costa 2005).

Na verdade, a "coleção colonial" da Cinemateca Portuguesa teve o seu ato inaugural no artigo de Pimentel, que atribuiu uma atenção especial a um conjunto de objetos fílmicos dispersos no acervo. Este gesto de (re) conhecimento, como tantas vezes acontece, foi simultaneamente produto do acaso - nas palavras de Pimentel, "caí naquela temática"24 - e de um interesse pessoal, já que a pesquisadora possuía ligações biográficas com 
uma antiga colônia. Na nossa primeira entrevista, Pimentel mencionou que as imagens que mais a haviam atraído, quando começou a visionar os documentários do ANIM, nem foram as imagens coloniais. Nessa mesma ocasião, porém, destacou o visionamento das imagens de Angola, de onde é natural: "voltar a ver a terra onde nasci, nos documentários, para mim é mais interessante." 25

Ao elemento biográfico e ao acaso juntou-se ainda o contexto de um debate internacional, que então dava os primeiros passos, sobre imagens deste tipo. A génese do artigo sobre a "coleção colonial" da Cinemateca foi a participação de Pimentel, em 2001, no congresso internacional da Federação Internacional dos Arquivos Fílmicos (FIAF), em Marrocos, para apresentar o filme Chaimite (1953). No ano anterior, o tema do congresso da FIAF, acolhido por Londres, tinha sido "Colonial Cinema: A Borrowed Film Heritage", resultando na publicação de um dossiê dedicado ao tema no Journal of Film Preservation, a revista da FIAF ${ }^{26} \mathrm{O}$ artigo de Pimentel viria a ser publicado no número seguinte. Segundo a pesquisadora, quando o artigo apareceu, passou a existir uma coleção colonial portuguesa: "Os outros todos falam das coleções coloniais, e nós tínhamos sido um país colonial e não falávamos nem de uma coisa nem de outra. Apareceu o artigo, passou a ter". ${ }^{27}$

Não é demais ressaltar o investimento pessoal que esteve na base da formação desta "coleção colonial", que a Cinemateca recentemente reconheceu, por ocasião da homenagem póstuma a esta pesquisadora. ${ }^{28}$ Como sempre acontece com empreendimentos pioneiros, a tarefa não foi fácil. Na nossa última conversa, Pimentel referiu as dificuldades que encontrou em face da escassez de imagens disponíveis para visionamento e a inexistência de fontes bibliográficas fiáveis. A pesquisa implicou um trabalho moroso de procura de ligações entre os filmes que haviam sido produzidos - segundo o Prontuário de José de Matos-Cruz (1989), única obra de referência à data - e as cópias que existiam nos depósitos. Outras pessoas, é certo, poderiam igualmente ter-se interessado, e de forma semelhante, pelos mesmos materiais. No entanto, os particulares do envolvimento de Pimentel conferem à "coleção colonial" da Cinemateca uma certa "dimensão autoral", que tem o mérito de colocar em evidência o carácter contingente e essencialmente construído desta coleção.

Como compreender, afinal, a existência, hoje reconhecida e disseminada, de uma "coleção colonial" da Cinemateca Portuguesa? ${ }^{29}$ O princípio ordenador desta "coleção" é indubitavelmente o elemento "colonial", que organiza - temática e discursivamente - os filmes, habilitando-os a poderem ou não entrar na "coleção". Assim, é condição de pertença mostrar os territórios coloniais (ou "ultramarinos") ${ }^{30}$ e ter sido produzido no período situado 
entre o aparecimento do cinema nesses territórios (delimitado pelo já referido Cultura de Cacau, de 1908) e as independências de cada colônia, por volta de 1975. No entanto, ainda que aparentemente claros, estes requisitos revelam-se insuficientes quando se trata de classificar materiais concretos, já que o próprio termo "colonial" flutua semanticamente entre uma acepção alegadamente neutra, que pretende "apenas" referir-se a um tempo e a um território específicos, e uma acepção fortemente politizada, que inclui nessa cronotopia um determinado regime de poder em relação ao qual é difícil não tomar uma posição.

Um exemplo da hesitação classificatória que esta instabilidade semântica frequentemente provoca emerge a propósito dos filmes amadores produzidos em contexto colonial. No artigo de 2002, Pimentel não refere o filme amador, talvez por não ocupar um lugar de relevo no período que analisa (1908-1935). ${ }^{31}$ Questionada, mais recentemente, sobre a existência de filmes amadores na "coleção colonial", a pesquisadora deu alguns exemplos de décadas mais tardias, mas revelou dificuldade em classificá-los como "filmes coloniais". ${ }^{32}$ O problema tem-se colocado a outros pesquisadores e arquivistas que trabalham com filmes semelhantes. É o caso de Nico de Klerk, que hesita em atribuir o rótulo de "filmes coloniais" às imagens amadoras de famílias que residiram na antiga colônia holandesa das Índias Orientais (atual Indonésia), hoje depositadas no arquivo holandês (De Klerk 2008a:142143). Para este investigador, estes filmes possuem uma expressividade única, que assenta não na capacidade de evocar, de forma inequívoca, estruturas abstratas como o colonialismo, mas no seu enraizamento no domínio da experiência, do particular e do quotidiano:

Being the closest visual records of the "grassroots" level of interaction in the colony, these films invite, if not force, us to suspend the wider colonial context and ask ourselves whether or to what extent they actually are colonial. I would maintain that the epithet "colonial" already destroys their power of expression. Besides bypassing generic distinctions, the term is not a merely neutral coordinate of the time and place of the film's origin. Rather, it triggers an anticolonial reflex, fed by current connotations of colonialism (and imperialism). The term tacitly turns these films into propaganda for colonial politics and policies. That ignores, first of all, all kinds of changes in and differences between colonial societies. Second, it identifies daily life with colonial ideologies (De Klerk 2008b:152, grifo no original).

A separação que De Klerk faz entre "vida quotidiana" e "ideologia colonialista" - a que corresponderão, respectivamente, os filmes amadores e os filmes de propaganda - é questionável, levantando mais problemas do que 
os que pretende resolver, especialmente se levarmos em conta a recepção destes filmes. Uma das particularidades do cinema amador (e mais ainda dos filmes domésticos) é o fato de se destinar a um público constituído por "espectadores-participantes" (De Klerk 2008b:148) que nutrem um interesse pessoal e afetivo pelas imagens. Ora, no relato da sua experiência de visionamento dos filmes de propaganda colonial, a investigadora da Cinemateca Portuguesa ressalta a facilidade que sentiu em estabelecer ligações identitárias e afetivas com os lugares e os ambientes representados que, como nota, têm um valor diferente para quem os conheceu em primeira mão ou através de memórias partilhadas em família. Vale a pena citar:

[O visionamento do bloco colonial] deu-me prazer, deu-me imenso prazer. Porque, inclusivamente, para mim é completamente diferente ver umas imagens de 1920 ou 30 de Luanda, onde eu cresci, onde eu tenho família, onde eu tive família, naquela altura - é completamente diferente ser eu a ver ou ser outra pessoa... Olha, lá está a casa que a tia não sei quantos falava... Completamente diferente (Entrevista com Joana Pimentel, Fevereiro de 2017).

Assim, a reação de Pimentel a estes filmes aproxima-se da reação de um "espectador-participante", que reconhece no "colonial" elementos familiares. Pelo contrário, o enfoque, próprio dos filmes amadores, numa esfera doméstica e familiar particular que exclui os espectadores não participantes acaba por provocar em Pimentel dúvidas sobre a inclusão desses filmes numa "coleção colonial". Podemos argumentar, como faz De Klerk, que o cinema colonial "não é colonial o tempo todo" (2008b:154), mas o problema de destrinçar quando o (não) é permanece.

Efetivamente, a "coleção colonial" da Cinemateca está implícita e explicitamente associada aos materiais de propaganda colonial, em particular, aos que resultaram diretamente da ação da AGC/AGU, principal órgão de propaganda colonial oficial, que, de resto, constituíram a base da coleção. ${ }^{33}$ Note-se que, no contexto do arquivo, o termo "coleção" é usado correntemente para referir as remessas que deram entrada ao mesmo tempo, originando numa mesma fonte - daí que se fale da "coleção da Tobis" para referir as remessas que vieram deste laboratório, da "coleção Lusomundo" para referir as remessas oriundas desta distribuidora, da "coleção do Museu Nacional de Etnologia", da "coleção da Fundação Calouste Gulbenkian", da "coleção do Ministério da Agricultura", e por aí adiante (cf. Baptista 2017:169).

Este uso corrente de "coleção" acaba por introduzir novos níveis de ambiguidade na expressão "coleção colonial", uma vez que lhe reconhece, simultaneamente, uma origem única e primordial - a coleção da AGC/AGU - 
e uma origem plural - as várias outras "coleções" que também a alimentam. Esta simultaneidade de fontes reforça a já referida instabilidade semântica em torno do "colonial", nomeadamente quando essas fontes dizem respeito a filmes que caem fora da esfera de produção oficial. É o caso, como se viu, dos filmes amadores, que suscitam dúvidas no momento da classificação. Mas é igualmente o caso dos filmes anticoloniais e pós-coloniais, que dialogam com o colonial a partir de outras perspectivas (muitas vezes fora das balizas periodológicas acima referidas ou sem mostrar imagens dos territórios coloniais), desafiando, de outras maneiras, as fronteiras que definem esta coleção.

Sem remeter para um referente que possa ser imediata e inequivocamente identificado e quantificado, ${ }^{34}$ a "coleção colonial" da Cinemateca existe, acima de tudo, como um efeito do discurso. Por isso é que ela é um objeto instável, refletindo a instabilidade dos princípios que a organizam, bem como as práticas e as visões, descontínuas e contraditórias, dos meios mais vastos (arquivísticos, culturais, artísticos e políticos) em que se move enquanto "coleção". Apesar de não se encontrar fisicamente separada do resto do arquivo, a "coleção colonial" da Cinemateca assemelha-se a um "objeto sintético", no sentido em que Elizabeth Edwards e Janice Hart (2004b:47-49) o definiram a propósito de uma caixa de fotografias - isto é, um objeto formado por outros objetos ligados entre si, que existem em interação uns com os outros e em interação com a instituição - ou quem quer que seja - que os decidiu juntar, ordenar e, dessa forma, dar-lhes um sentido.

A análise desta "coleção", do todo, dependerá sempre, por conseguinte, da análise das suas partes (os filmes). O reverso também se aplica, já que cada parte é devedora, nos significados e nas percepções que suscita e nos usos a que se presta, do todo, que é sempre maior do que a soma das partes (cf. Edwards \& Hart 2004b:47). Por outras palavras, tomadas enquanto parte de uma "coleção colonial", as imagens em causa ganham sentidos que, de outra forma, não seriam facilmente perceptíveis. Por outro lado, elas correm o risco de verem omitidas outras ligações e interações exteriores à ordenação em que se encontram inseridas, perdendo aspectos da sua singularidade que poderiam nos ajudar a compreender melhor as questões em análise.

\section{As lições materiais do arquivo}

O caráter construído e essencialmente indefinido da coleção colonial da Cinemateca assume formas particularmente interessantes quando considerado a partir das muitas e diversas materialidades que constituem o arquivo. Para começar, a materialidade dos filmes é impossível de ignorar 
numa visita aos arquivos, colocando-nos perante fatos (entendidos aqui enquanto constatações de âmbito observacional) que uma noção de filme confinada aos seus conteúdos imagéticos nem sempre nos permite apreender e muito menos apreciar. É nesse sentido que falo em "lições materiais" do arquivo, elaboradas em torno de três desses fatos: o caráter fragmentário e ontologicamente instável quer do arquivo, quer dos seus filmes; a escassez de imagens coloniais; e a disposição física e espacial dos materiais - o fato de "estar tudo junto", nas palavras de Pimentel. ${ }^{35}$ A análise, separada ou em conjunto, destes três fatos oferece-nos importantes lições não apenas sobre o arquivo em si, mas sobre o conhecimento que procuramos produzir quando a ele recorremos - neste caso, o conhecimento que procuramos produzir sobre um determinado período, um determinado regime, um determinado modo de vida ("colonial"), por intermédio de um conjunto de objetos de interesse visual acumulados num mesmo arquivo, antes mesmo de visionarmos os seus conteúdos.

O caráter fragmentário da "coleção colonial" da Cinemateca Portuguesa chega-nos, empiricamente, por várias vias: nas obras de que possuímos registros, mas das quais não existem materiais; nas cópias que existem, mas que não podemos visionar por questões de preservação; nas obras incompletas, cujo visionamento só pode ser parcial ou interrompido; na ausência de registros a acompanhar as obras - os que existiram e se perderam e os que nunca foram feitos. Todos estes casos confirmam a condição do arquivo de imagens em movimento como um lugar de fragmentos, lembrando-nos que o arquivo apenas guarda o que lhe foi confiado e, dessa parte, apenas o que lhe foi permitido resgatar à ação destruidora do tempo. Por fim, uma parte significativa do acervo de um arquivo de imagens em movimento é composta literalmente por "filmes-fragmento" (cf. Moyer 2007; Deprez 2014) sobre os quais pouco ou nada se sabe.

Por outro lado, o arquivo de imagens em movimento também guarda uma multiplicidade de materiais repetidos ou relacionados entre si, vestígios das remontagens (uma prática comum, por exemplo, nas distribuidoras, desde os inícios do cinema) a que algumas imagens, sob o mesmo título ou não, eram sujeitas. Ou seja, o arquivo mostra-nos que as imagens em movimento são entidades menos estáveis, unas e acabadas do que os termos que geralmente usamos para designá-las ("filme", "obra") sugerem. Para além de um lugar de fragmentos, o arquivo de imagens em movimento é também um lugar de permanente e manifesta instabilidade.

Significa isto que contemplar o arquivo de imagens em movimento é contemplar os limites do nosso conhecimento, já que o arquivo torna claro os limites daquilo que tendemos a tomar, sem quaisquer garantias, como uma 
totalidade estável que terá existido algures no passado, mas que não existe mais. O recente interesse pela temática das ruínas no contexto do arquivo colonial (Stoler 2008, 2013) tem vindo a colocar em causa esta ideia de totalidade - não para lamentar a sua ausência ou impossibilidade, mas para reconhecer o alcance teórico dessa ausência e explorar os seus significados, com o objetivo de transformar os fragmentos desordenados do arquivo em objetos geradores de sentidos históricos e etnográficos (cf. Ladwig et al. 2012:6). Nesta perspectiva, a condição fragmentária e instável do arquivo acaba por revelar-nos a condição fragmentária e instável do próprio conhecimento (o nosso e o de então). Ou seja, os limites e os fracassos do arquivo colonial acabam por conter em si a capacidade de expor e enunciar os limites e os fracassos do próprio projeto colonial (Ladwig et al. 2012:3).

O segundo fato que ressalta do arquivo é a escassez de imagens coloniais. Apesar das dificuldades que se colocam à sua classificação e, consequentemente, à sua quantificação, a coleção colonial da Cinemateca, entendida no sentido mais restrito, aponta para um universo francamente pequeno. Refiro-me ao número reduzido de imagens que sobreviveram até os nossos dias, consequência da degradação dos materiais que as suportam e da negligência de que foram alvo ao longo dos anos, mas também da quantidade limitada de imagens que terão sido produzidas e que terão efetivamente circulado no seu tempo. É fácil, no afã de viragens teóricas que nos convêm, proclamar o "excesso visual das colónias" (Vicente 2014:18). Uma abordagem materialista das imagens fixas e em movimento recomenda, porém, mais cautela (cf. Martins 2012) ao oferecer-nos lições inestimáveis sobre a fragilidade dos suportes materiais, a condição volumosa, pesada e tecnologicamente exigente dos equipamentos, o caráter dispendioso da fotografia, e ainda mais do cinema, e em geral as contingências históricas que, em diferentes graus, nas diferentes épocas e nos diferentes lugares, impuseram limites ao acesso a estes dispositivos, tanto no nível da produção como no da recepção.

Note-se que o aparelho colonial, tantas vezes apontado como veículo de difusão da fotografia e do cinema, funcionou igualmente como um dos seus principais obstrutores. Em Portugal, depois do Acto Colonial (1933), filmar nas colônias sem a participação do Estado estava fora das possibilidades financeiras dos produtores portugueses (Pimentel 2002:29) e a posse de câmaras era muitas vezes alvo de controlo ou mesmo proibição - como se verificava na Diamang, a Companhia de Diamantes de Angola (Porto 2004:115, 130; Porto 2001:39). O testemunho de profissionais do sector sugere que, nos anos 40 e 50, filmar em Angola era uma atividade rara, dominada por práticas improvisadas e "amadoras".36 Por fim, sabemos que algumas 
imagens em movimento de que existem registro circularam muito para lá do ano ou até da década em que foram produzidas, ${ }^{37}$ o que sugere falta de recursos para se produzirem novos materiais ou ausência de interesse para fazê-lo. Ou seja, por razões técnicas, econômicas, políticas ou outras, filmar nas colônias era um empreendimento relativamente raro.

Tal como acontecia com outros impérios, ${ }^{38}$ também o Estado português se terá visto dividido entre, por um lado, a vontade de controlar a representação dos seus territórios coloniais e, por outro, a relutância em envolver-se com um sector dispendioso e complexo, caracterizado por necessidades e dinâmicas próprias difíceis de controlar, também elas sujeitas aos caprichos e à imprevisibilidade do público. Muitas vezes, as imagens eram resultado do esforço de entusiastas isolados, tais como militares e funcionários, que tentavam atrair apoios do Estado através da defesa das "virtudes pedagógicas do cinema" (Pimentel 2002:25), ${ }^{39}$ ou de profissionais que exploravam, dentro dos limites ideológicos e materiais do regime, as oportunidades de financiamento e distribuição que iam surgindo. ${ }^{40}$ Não obstante o interesse propagandístico no cinema, bem patente nos filmes encomendados para exposições internacionais (Pimentel 2002:26), nada garantia ao Estado como as imagens iriam ser recebidas, sobretudo quando eram objeto de exploração comercial, o que desencorajava empreendimentos duradouros e investimentos mais audazes. Em face da expansão do modelo estético, narrativo e de entretenimento de Hollywood, nem sempre era fácil agradar a públicos habituados a filmes com elevados valores de produção e fórmulas narrativas eficazes. ${ }^{41}$

Talvez a escassez de imagens sobre os territórios coloniais explique o fato de os mesmos filmes circularem em diferentes espaços de exibição: filmes de instrução eram projetados (frequentemente para frustração dos espectadores) em espaços comerciais vocacionados para o entretenimento; filmes comerciais passavam em salas geridas por missões religiosas, causando o protesto dos exibidores profissionais por não pagarem impostos (cf. Domingos 2012:404); e algumas palestras acadêmicas faziam-se acompanhar de filmes de propaganda colonial (cf. Dias 2014:201). ${ }^{42}$ Todas estas contingências são passíveis de emergir durante o escrutínio etnográfico do arquivo. Com efeito, o reduzido número de imagens em movimento da "coleção colonial" do ANIM sugere o caráter irregular e raro da captura cinematográfica - mesmo quando acompanhada de intuitos científicos ou resultante de políticas culturais emanadas do Estado colonial. Sugere também o esforço que era filmar nos lugares dispersos do também fragmentário Império Português, que se estendia geograficamente, de forma descontínua, "do Minho a Timor". Em última análise, a magnitude desse esforço, bem como os parcos resultados que alcançava contradizem o discurso oficial, que atribuía a esses lugares um caráter "provincial" e "dis- 
trital" de pendor quase doméstico, a fim de podê-los apresentar como parte de um todo que se acreditava (e desejava) coeso e "indivisível".43

O que nos traz, finalmente, à terceira lição do arquivo, assente na constatação de que, como Pimentel fez notar, "está tudo junto". Com efeito, quando dela nos acercamos a partir do arquivo, a "coleção colonial" da Cinemateca se apresenta menos como um fato concreto e mais como um efeito discursivo, uma entidade informe com fronteiras difíceis de definir que podem ser levadas ao extremo de incluir todos os filmes do arquivo. A este respeito, Pimentel cita o investigador Paulo Cunha, que sugeriu que "num país colonial é tudo colonial", acrescentando: "aqui no nosso arquivo, se formos a ver, é tudo colonial no que diz respeito à produção portuguesa está tudo junto". ${ }^{44}$ Para além de reforçar o caráter arbitrário desta "coleção", que depende sempre do princípio organizador que escolhemos adotar, o "estar junto" dos materiais faz-nos querer refletir sobre o que liga esta "coleção" ao resto do arquivo. De que forma é que ela é parte de um todo ou, pelo contrário, algo que se destaca do resto? Curiosamente, a pergunta é evocativa das críticas que têm vindo a ser feitas por autores como Frederick Cooper e Ann Laura Stoler (1997) à tendência para traçar uma linha de separação conceptual e metodológica entre "colônia" e "metrópole", desse modo tornando permanentes descontinuidades espaciais que resultam de construções teóricas e visões políticas historicamente situadas.

Mas outras perguntas impõem-se. Para um outro nível de análise, qual o lugar que esta "coleção" ocupa no conjunto do arquivo? Se, no labor quotidiano do arquivo, ela é percepcionada como apenas mais uma entre as muitas coleções que clamam a sempre mui solicitada e repartida atenção dos arquivistas e conservadores, que feições assume esta "coleção" quando passa a ser observada na distância de um estudo etnográfico? De que forma é que podemos vê-la como um suplemento ou excesso de um acervo que se constrói no quadro de um projeto nacional de recolha, preservação e valorização de um cinema português? Qual o valor e o significado que ela possui enquanto legado de um passado que é também comum a nações hoje independentes? De que patrimônios (materiais e imateriais) é esta "coleção" hoje representativa, ou até detentora?

\section{Considerações finais}

Na esteira da investigação que se tem desenvolvido nas últimas décadas sobre a fotografia e os arquivos fotográficos, este artigo encara a visita etnograficamente motivada ao arquivo de imagens em movimento como 
condição metodológica necessária para o estudo das imagens coloniais. O que se propõe, em suma, é uma abordagem antropológica e materialista às imagens em movimento e aos seus arquivos. Tal como a fotografia, também as imagens em movimento pedem que levemos em conta a sua materialidade. Intangíveis durante a projeção, na qual emergem sob a forma de imagens-representação, elas existem num complexo sistema de materialidades que percorrem as fases de produção, distribuição e projeção. Se, durante esta última - com os espectadores imersos num ambiente escuro, de olhar fixo na tela - a condição material dos filmes não é imediatamente perceptível, num museu de cinema e nos seus arquivos ela é impossível de ignorar. Aqui, a materialidade dos filmes salta à vista - nas estantes dos depósitos, nas latas e cassetes dos vários formatos, nas máquinas e nos aparelhos que assistem os técnicos de conservação nas suas várias tarefas, nas salas de visionamento - interpelando-nos a cada momento (Sampaio 2015).

Um dos problemas com os quais se têm confrontado os investigadores de cinema colonial é a necessidade de justificarem o interesse por imagens que, na maior parte das vezes, são julgadas por aquilo que não mostram (MacCabe 2011:8) - uma tendência também notória nos estudos de fotografia em contextos semelhantes (ex. Varanda 2007). Ao desviar o enfoque dos conteúdos para os objetos, abre-se a possibilidade de pensar estes filmes, tal como as fotografias, como "objetos socialmente salientes" (Edwards \& Hart 2004a:5), que foram adquirindo determinados significados e chamados a cumprir determinadas funções ao longo das suas carreiras biográficas.

Sem querer negar ou diminuir a importância dos vários mecanismos que tiveram por objetivo o controlo apertado das imagens (tais como a encomenda fechada, a censura e a autocensura), que merecem ser estudados por si sós, é importante considerar de que forma é que os conteúdos dos filmes - isto é, aquilo que de fato mostram - eram por vezes menos importantes do que o valor performativo que lhes era atribuído num dado momento. É provável que a vontade de exibir imagens das colônias em feiras internacionais, para desse modo reclamar, através do dispositivo cinematográfico, um estatuto de país moderno e imperial inter pares, pudesse pesar mais do que a vontade de mostrar este ou aquele conteúdo - ainda que os dois aspectos não se possam, evidentemente, separar. Um estudo empírico e localizado sobre objetos-filmes do arquivo poderá revelar "performances de poder" semelhantes às que Nuno Porto (2004:125) encontrou associadas a algumas fotografias.

A análise das imagens "coloniais" da Cinemateca Portuguesa só poderá beneficiar se levarmos em conta esta vertente material até agora pouco ou nada explorada. Falar desta "coleção" implica falar de um conjunto de objetos que existem, de forma tangível, nos depósitos do ANIM. Mas implica 
também apurar as "condições da sua produção" (Cunha 2004:293), nos moldes sugeridos por antropólogos que estudaram outros arquivos. Ou seja, falar da "coleção colonial" da Cinemateca Portuguesa implica reconhecer 1. que o que faz destes objetos uma "coleção" são os princípios de organização a que foram submetidos (e não os objetos em si); 2 . que esses princípios de organização não mitigam (pelo contrário, acentuam) o cariz essencialmente fragmentário desta "coleção".

O primeiro destes aspectos diz respeito ao "carácter eminentemente construído dos arquivos" e à necessidade de "desnaturalizar" os arquivos (cf. Castro, 2005; Frehse, 2005). Como procurei demonstrar, é difícil definir os limites quantitativos e qualitativos da "coleção colonial" da Cinemateca, que se assemelha mais a um "objeto sintético" (Edwards \& Hart, 2004b) do que propriamente a um objeto arquivístico. Ou seja, apesar de não estar separada das outras imagens do arquivo, a "coleção colonial" possui uma lógica interna (na relação entre as partes) e externa (na relação do todo com a instituição e com outros agentes) que lhe confere um espaço efectivamente à parte. Este espaço pertence à ordem do pensamento e do discurso, mas não impede que a "coleção colonial" seja tratada como uma entidade sólida, efetiva e real. Para uma pesquisadora conhecedora do arquivo, como a minha informante, a "coleção colonial" da Cinemateca carece de contornos materiais claros - não por acaso, para que pudesse existir, ela teve que ser nomeada. Pimentel fê-lo num artigo que, como a própria reconheceu, foi uma espécie de ato fundador desta "coleção". Não obstante todas estas contingências, a "coleção colonial da Cinemateca" circula agora como se fosse um objeto arquivístico em pleno - o nome é, enfim, tomado pela coisa.

O segundo aspecto - o cariz fragmentário desta "coleção" - está patente numa série de indícios: não apenas nos filmes que faltam (por terem sido perdidos) ou nas partes de filmes que faltam (por se terem degradado), mas também em tudo aquilo que não conhecemos sobre eles. Refiro-me, em particular, aos "sistemas materiais" a que estas imagens pertenceram e às suas "carreiras biográficas" (Porto 2004:113) que, com o passar do tempo, se tornam cada vez mais difíceis de reconstituir. A escassez de informação que existe sobre estes materiais - quem os realizou, produziu, fotografou, e em que ano; onde foram projetados e em que condições - é uma evidência verdadeiramente esmagadora. No entanto, essa evidência pode adquirir um valor produtivo. Com efeito, a materialidade do arquivo incentiva-nos a pensar a "coleção colonial" como um conjunto de fragmentos que sobraram da relação entre o cinema e as colônias portuguesas e que requerem, agora, métodos interpretativos para fazerem sentido. Não se pretende com isto remeter para uma qualquer totalidade no passado distante, que julgamos poder recuperar, 
peça a peça, como num puzzle. Pelo contrário, as limitações epistemológicas que encontramos, hoje, no encontro etnográfico com o arquivo, servem de alerta para limitações similares que terão estado operacionais em tempos passados. Por exemplo, a escassez, a instabilidade e a fragmentariedade dos materiais que observamos no arquivo indiciam um regime cinematográfico colonial de produção limitada, instável e intermitente, apontando mesmo para um envolvimento cauteloso, errático ou até indiferente do Estado colonial com o sector. Esta hipótese terá que ser testada através de estudos de caso empíricos, que atualmente ainda escasseiam.

Os filmes existem, agora, enquanto coleção museológica. O princípio de organização que lhes deu forma - a pertença a um espaço-tempo e a uma cultura "colonial" - tem efeitos e implicações várias. Na esteira do argumento que Sassoon (2004:194) elaborou para a fotografia, é importante reconhecer que as práticas de formação e gestão de coleções de imagens em movimento têm consequências para o tipo de investigação que podemos (ou não), a partir delas, desenvolver. Como o investigador Nico de Klerk (2008b) sugeriu em relação aos filmes amadores produzidos em contexto colonial, ao serem incluídas numa "coleção colonial", algumas imagens poderão ver ignorados aspectos importantes da sua "expressividade". A pertença a uma "coleção" poderá ainda orientar os investigadores em direcção a certas leituras, em detrimento de outras que poderiam revelar-se tão ou mais vantajosas para o conhecimento que se deseja alcançar a partir dessas imagens.

Por fim, o princípio de organização que subjaz à constituição desta "coleção" coloca filmes e coleção numa espécie de "terra de ninguém" (De Klerk 2008b:152), no vazio que separa o cinema da nação ex-colonizadora (Portugal) do cinema de cada uma das novas nações ex-colonizadas (Angola, Moçambique etc.). Nem em um nem no outro encontra o filme colonial um lugar. Ainda que este gesto ordenador possa ajudar a clarificar alguns aspectos e relações, é importante perceber o que há de excepcional nestas imagens para justificar que sejam, deste modo, isoladas. Será esta ordenação a que melhor contribui para a compreensão destas imagens e do tempo histórico que as viu nascer?

A abordagem materialista que aqui se propõe não se encontra, porém, confinada a um tempo pretérito - nem o da produção das imagens nem o da sua constituição enquanto parte de uma coleção. O tempo da investigação é necessariamente o tempo presente. Assim, falar de "filme colonial" ou "coleção colonial" não implica apenas inquirir sobre o significado, nos nossos dias, do termo "colonial" e o que isto nos diz sobre os filmes, isolados ou integrados numa certa "coleção". Implica outrossim perguntar o que é que estes termos e objetos dizem sobre nós mesmos - investigadores, conserva- 
dores, programadores e consumidores - no momento em que lhes prestamos uma atenção especial. Por outras palavras, se estas imagens serviram usos passados, de que agencialidades são elas agora mediadoras? De que modo é que estes objetos-filmes e este objeto-coleção participam ou poderão vir a participar no "mercado de patrimônio" que atualmente dá forma às recomendações internacionais que consideram as imagens em movimento como "parte integrante do patrimônio das nações" (Costa 2005:64-65)? O escrutínio das práticas de formação e gestão de coleções de imagens em movimento poderá ajudar-nos a melhor compreender o que está em causa e de que forma podemos avançar nesta importante e ainda pouco estudada área.

Recebido em 02 de maio de 2018

Aprovado em 30 de outubro de 2018

Sofia Sampaio

Investigadora auxiliar no Centro em Rede de Investigação em Antropologia (CRIA) do Instituto Universitário de Lisboa (ISCTE-IUL), onde integra o grupo de investigação Práticas e Políticas da Cultura e o Núcleo de Antropologia Visual e das Artes (NAVA). E-mail: <psrss@iscte-iul.pt>

\section{Agradecimentos}

Agradeço à Joana Pimentel pelo tempo que disponibilizou para as entrevistas e a paciência com que suportou inquirições quiçá abstrusas. Sem a sua colaboração, este artigo não teria sido possível - certamente não nesta forma. As interpretações que avanço em face dos dados recolhidos, bem como as eventuais falhas e omissões são da minha inteira responsabilidade. Agradeço igualmente à Ema Pires, que lançou o desafio para este texto, bem como aos revisores da revista Mana pelos comentários atentos, pertinentes e construtivos, que me permitiram aprofundar e clarificar alguns argumentos. Esta pesquisa foi financiada pela Fundação para a Ciência e a Tecnologia (FCT, Portugal), no âmbito do contrato "Investigador FCT" (IF/00313/2013) e do projeto estratégico do Centro em Rede de Investigação em Antropologia (UID/ANT/04038/2013).

\section{Post Scriptum}

Dedico este artigo à Joana Pimentel, numa homenagem sentida ao trabalho que realizou no arquivo para que outros (como eu) pudessem continuar a pesquisar, nos escombros cinematográficos do passado, as muitas inquietações do presente. 


\section{Notas}

1 A título de exemplo, veja-se, para a fotografia, Ryan (1998), Maxwell (1999) e Vicente (2014); para o postal, Geary e Webb (1998); para o cartaz, Kothari (2014) e Buck (2015); para o selo, Jeffery (2006) e Cusack (2005).

2 É esta a premissa de Nuno Porto, segundo o qual, "as culturas coloniais caracterizaram-se por um elevado nível de indeterminação e experimentação social, e não simplesmente por uma agenda prescrita" (2004:114, minha tradução) ["colonial cultures were characterised by a high degree of indeterminacy and social experimentation, rather than simply a prescribed agenda"]. A principal referência deste autor é Thomas (1994), mas veja-se também a antologia editada por Cooper e Stoler, sobretudo a introdução (1997).

3 A fim de contrariar esta tendência, Mitchell propõe que se trate a cultura visual e as imagens como "mediadores em transações sociais", o que significa que "a construção social do campo visual tem que ser continuamente reconfigurada enquanto construção visual do campo social" (2002:175, minha tradução). ["This approach would treat visual culture and visual images as go-betweens in social transactions (...) And this means that the social construction of the visual field has to be continuously replayed as the visual construction of the social field"].

4 Nota do revisor: será mantido no texto a ortografia de Portugal, com suas pequenas diferenças em relação ao português do Brasil consentidas pelo Novo Acordo Ortográfico da Língua Portuguesa.

5 A própria relação entre o poder colonial e os agentes de conhecimento nomeadamente no que diz respeito à chamada "ciência colonial" - tem sido objeto de reavaliação. Veja-se o excelente artigo de Cláudia Castelo (2012), que traça o panorama dos estudos internacionais e nacionais sobre esta temática.

6 É importante notar que o agrupamento de certas imagens sob o signo do colonial é uma operação classificativa realizada a posteriori. Ou seja, a categoria "imagens coloniais" resulta, fundamentalmente, de uma intervenção analítica retrospectiva, lançada a partir da pós-colonialidade. Este aspecto é evidente em alguns estudos (ex. Mayer 2002), mas tende a permanecer implícito. Sobre a oscilação neste artigo entre o uso e a ausência de aspas para me referir a estas imagens, veja-se a nota 11.

7 Já em 2008, De Klerk assinalava a indiferença a que as humanidades e as ciências sociais haviam votado aos filmes produzidos em contexto colonial, mesmo durante a explosão dos estudos pós-coloniais. Quando esse interesse existiu, confinou-se à história do cinema e incidiu sobre a ficção (De Klerk 2008a:142; 2008b:150). O mesmo se pode dizer do caso português (cf. Seabra 2011). Nos últimos anos tem crescido o interesse internacional por este objeto, a que Portugal não ficou indiferente, como atesta o trabalho de Piçarra (ex. 2015) e o projeto, em curso, coordenado pelo antropólogo Nuno Domingos sobre o império colonial português e a cultura popular urbana. 
8 Outras línguas, como o inglês, distinguem entre photograph (objeto) e photography (prática).

9 Não por acaso, o cinema era conhecido como "fotografia animada" nos primeiros anos da sua existência (cf. Costa 2005:60).

10 Como este parágrafo deixa claro, o escopo da minha análise restringe-se ao formato analógico, excluindo a imagem digital (fixa e em movimento) que, no período em análise, ainda não existia. O digital veio trazer alterações profundas à percepção e aos usos das imagens (cf. Sassoon 2004 sobre a fotografia digital) dos quais não me ocuparei.

11 Veja-se o recente dossiê da revista Comunicação e Sociedade, intitulado "Imaginários coloniais: propaganda, militância e 'resistência' no cinema" (Piçarra et al. 2016), no qual estas tendências são evidentes. Mas veja-se também, para uma abordagem alternativa, o trabalho da antropóloga Catarina Alves Costa (2015).

12 Ao longo do artigo, recorro a aspas duplas para assinalar a instabilidade semântica de termos como "coleção", "colonial", e "coleção colonial". Trato esta instabilidade, que tem origem na minha principal interlocutora (cf. a epígrafe a este artigo), como um dado etnográfico relevante que, por isso mesmo, não é minha intenção resolver. Outras expressões como "imagens coloniais", "filmes coloniais" e "cultura colonial" poderão ou não aparecer entre aspas, dependendo do uso que lhes estiver a ser dado: entre aspas, se remetem para citações anteriores ou estão a ser alvo de "desnaturalização" (Castro 2005); sem aspas, se estão a ser tomados pelo seu valor aparente e de uso corrente (isto é, o seu face value).

13 Veja-se o filme Kora, de Jorge Miguel Correia Carvalho (2014), que contém imagens que acompanharam a viagem de um destes instrumentos de cordas da Guiné-Bissau para o Museu Nacional de Etnologia, em Lisboa. O documentário vem mediar a "devolução" deste objeto (e das suas imagens) aos descendentes do músico que, nas imagens de arquivo, aparece a tocar o instrumento. A função originalmente adscrita às imagens de arquivo de contextualizar o objeto é agora suplementada (subvertida?) pelo novo "encontro etnográfico" e pela nova performance, também captados em imagens, que oferecem um novo contexto quer ao objeto, quer às imagens de arquivo, abrindo novas possibilidades de leitura.

14 Sendo que circulação é entendida não como "a 'disseminação', 'transmissão' ou 'comunicação' de ideias, mas os processos de encontro, poder e resistência, negociação, e reconfiguração que ocorrem em interações culturais cruzadas" (Raj 2013:343, minha tradução) ["by circulation we understand not the 'dissemination', 'transmission', or 'communication' of ideas, but the processes of encounter, power and resistance, negotiation, and reconfiguration that occur in cross-cultural interaction"].

15 Nota do revisor: Permanecerão em maiúscula os meses como são registrados em Portugal.

16 Esta secção teve como principais fontes o artigo de Pimentel (2002), bem como duas longas entrevistas com esta pesquisadora em Novembro de 2014 e Fe- 
vereiro de 2017. A primeira das entrevistas contou com a colaboração de Marcos Cardão, Gonçalo Mota e Sérgio Bordalo e Sá.

17 A Companhia Portuguesa de Filmes Sonoros Tobis Klangfilm, mais conhecida como Tóbis Portuguesa, foi criada em 1932. Contava com uma sede, em Lisboa, e um complexo de estúdios e laboratórios, nos arredores da cidade. Foi um dos principais laboratórios de cinema em Portugal até o seu encerramento, em 2012.

18 O processo de prospecção geral, que visava sobretudo aos acervos institucionais, foi anterior a 1996, mas só a partir daí é que se começou a receber a maior parte das coleções. Segundo Pimentel, algumas coleções demoraram 18 anos, desde o primeiro contato, a chegar ao arquivo (entrevista de Novembro de 2014).

19 Da ficção, Pimentel destaca Feitiço do Imperio (1940), de António Lopes Ribeiro, "o grande filme colonial português", e Chaimite (2002:23).

20 A título de exemplo, os documentos associados à produção fílmica da AGC/ AGU foram integrados aos arquivos históricos do ultramar que, em 2002, se encontravam "inacessíveis para consulta" (Pimentel 2002:22). Sobre a desagregação de diferentes materiais de uma mesma remessa ou coleção como uma prática comum, veja-se Ladwig et al. (2012) e Vicente (2012:435).

21 De 2002 para cá verificaram-se algumas entradas, mas poucas (à razão de um a dois títulos por ano). Exemplos são a entrada (ou a identificação) de jornais de atualidades de que não se conheciam exemplares; a entrada de imagens da excursão a Angola do Professor Wittnich Carrisso (1886-1937), em 1928-29; e a entrada de filmes amadores, como os do conhecido fotógrafo "Quitos", ou Francisco Jorge Esperança Júnior (1926-2012), sediado no Lobito, e os do Major Almiro Canelhas. Segundo Pimentel "o grosso já cá estava" (entrevista de Fevereiro de 2017).

22 Não estando limitada a obras de produção nacional, a Cinemateca Portuguesa define, de forma clara, como sua principal missão o "interesse da salvaguarda do património artístico e histórico português". Veja-se: http://www.cinemateca.pt/ Cinemateca/Missao-e-Actividades.aspx (Acesso em 20/04/2018). A prática vigente parece favorecer uma abordagem inclusiva, de "tudo aceitar", pelo menos aquando da recepção dos materiais (entrevista a Joana Pimentel, Fevereiro de 2017).

23 Segundo Pimentel, esta recorre sobretudo à localização geográfica das imagens (ex. "Angola") ou à identificação de eventos históricos importantes (ex. "guerra colonial"). Entrevista de Fevereiro de 2017.

24 Entrevista de Fevereiro de 2017.

25 Entrevista de Novembro de 2014.

26 Journal of Film Preservation, 63, Outubro de 2001. Disponível em: https:// www.fiafnet.org/pages/Publications/JFP-Archive.html\#63. Acesso em 10/09/2018.

27 Entrevista com Joana Pimentel, Fevereiro de 2017. 
28 Joana Pimentel faleceu em Junho de 2018. Na programação de Setembro desse ano, a propósito da sessão pública realizada em seu tributo, a Cinemateca elogiou o "trabalho seminal" da pesquisadora, destacando a sua ação "em prol da salvaguarda e do conhecimento das imagens em movimento de temática colonial" (p. 14). Disponível em: http://www.cinemateca.pt/getattachment/0962c024-79a6-479bb5b2-b7d61e4c8c48/setembro-2018.aspx. Acesso em 10/09/2018.

29 Veja-se, a título de exemplo, a programação que a Cinemateca Portuguesa-Museu do Cinema apresentou entre 2015 e 2016, em colaboração com a Aleph - Rede de Acção e Investigação Crítica da Imagem Colonial, intitulada: "A colecção [sic] colonial da Cinemateca: Campo, contracampo, fora-de-campo".

30 Como passaram a ser oficialmente designados a partir de 1951.

31 A história do filme amador em Portugal está por fazer, mas terá sido influenciada pela entrada da Eastman Kodak no mercado não profissional e doméstico (que já existia, mas de forma residual) com o lançamento do filme de 16mm (1923), a que se seguiram os formatos de 8mm (1931) e o Super 8 (1965). A discussão que se segue diz respeito aos filmes domésticos ou de família produzidos nas colônias durante as décadas de 1960 e 1970.

32 Entrevista de Fevereiro de 2017.

33 Esta associação é evidente para Pimentel, para quem a coleção "é o universo AGU ou da propaganda que diz respeito às colónias" (entrevista de Fevereiro de 2017).

34 Como refere Pimentel, não se encontrando separada do resto do acervo, a "coleção colonial" é de difícil quantificação. Não obstante, se tomada num sentido restrito, ela não é muito grande, já que as imagens das colônias sempre foram "raras" (entrevista de Fevereiro de 2017). Noutra ocasião, Pimentel avança uma estimativa de cerca de 3.000 títulos, num universo de produção nacional que ronda os 17.750 filmes (comunicação pessoal).

35 Entrevista de Fevereiro de 2017

36 Como pude constatar em entrevistas com o operador de câmara João Silva (1916-2015), que filmou em Angola a partir de 1950. As suas imagens deram origem a documentários e às Actualidades de Angola, montados e produzidos em Lisboa. Para um excerto destas entrevistas, que realizei com Gonçalo Mota e Sérgio Bordalo e Sá, em Novembro de 2014, veja-se Sampaio (2017).

37 É o caso das imagens da Índia Portuguesa e de Macau que o cineasta amador Manuel Antunes Amor fez nos anos 20, que terão sido as primeiras e as únicas que os portugueses viram destes sítios até o início dos anos 50 (Pimentel 2002:25). A recepção, no ANIM, das mesmas imagens por via de diferentes distribuidoras (Pimentel 2002:27) é também indiciadora da escassez destas imagens.

38 Veja-se, por exemplo, os estudos de caso de Woods (2001) e Rice (2011) sobre o império britânico. 
39 Esta relação de mútua, mas cautelosa, "sedução" entre profissionais-amadores-entusiastas e o Estado não é exclusiva nem dos regimes ditatoriais nem do campo cinematográfico.

40 Este parece ter sido o caso de Miguel Spiguel (1921-1975) ao longo da sua atividade de realizador e produtor de filmes turísticos coloniais, nos anos 60 e 70, segundo o que pude apurar em entrevista (Dezembro de 2014) com um familiar seu. Para um excerto desta entrevista, veja-se Sampaio (2017).

41 Segundo Pimentel (2002:28), o público era lesto a rejeitar os filmes de produção nacional, considerados inferiores quando comparados com produções internacionais como La Croisière Noire (1926), os documentários da produtora alemã UFA (1917-1945), os filmes "etnográficos" ou exóticos de Flaherty, Murnau e Shoedsack, e tantos outros, que alimentavam o stock de imagens coloniais que circularam globalmente durante a primeira metade do século XX.

42 A ambiguidade em relação ao público-alvo estava muitas vezes na origem do fracasso de alguns projetos estatais de cinema colonial. Veja-se o caso da série de filmes produzidos pela British Instructional Films entre 1925 e 1928 (Rice 2011).

43 O fato de jornais de atualidades nacionais, como o Jornal Português (19381951), produzido pela Sociedade Portuguesa de Actualidades Cinematográficas (SPAC) para o Secretariado da Propaganda Nacional (SPN), praticamente não mostrarem imagens das colônias é outro exemplo deste tipo de contradição. Veja-se Sampaio (2016:469).

44 Entrevista de Fevereiro de 2017. 


\section{Referências bibliográficas}

APPADURAI, Arjun. 1986. The Social Life of Things: Commodities in Cultural Perspective. Cambridge: Cambridge University Press.

BAPTISTA, Tiago. 2017. "As coleções de não-ficção da Cinemateca num relance: Preservação, acesso e investigação". In: S. Sampaio (org.), Viagens, Olhares e Imagens: Portugal 1910-1980. Lisboa: Cinemateca Portuguesa. pp. 168-171.

BOUQUET, Mary. 2001. "Academic anthropology and the museum. Back to the future. An introduction". In: M. Bouquet (org.), Academic Anthropology and the Museum. Back to the Future. Oxford and New York: Berghahn Books. pp. 1-19.

BUCK, Tim. 2015. "Imagining Imperial Modernity in British Colonial West Africa: Gerald Spencer Pryse's Work for the Empire Marketing Board". Art History, 38 (5):940-963.

CARVALHO, Jorge M. Correia. 2014. Kora, 71', Guiné-Bissau/ Portugal (filme).

CAStElO, Cláudia. 2012. "Ciência, Estado e Desenvolvimento no Colonialismo Português Tardio". In: M.B. Jerónimo (org.), O Império Colonial em Questão (sécs. XIX-XX): Poderes, saberes e instituições. Lisboa: Edições 70. pp. 349-387.

CASTRO, Celso. 2005. "A trajetória de um arquivo histórico: reflexões a partir da documentação do conselho de fiscalização das expedições artísticas e científicas no Brasil". Estudos Históricos, 36:33-42.

COSTA, Catarina Alves. 2015. "Margot Dias: o trabalho de organização, contextualização e sonorização do arquivo" e "Guia de Filmes". In: Publicação anexa ao DVD Margot Dias, Filmes etnográficos 1958-1961.
Lisboa: Cinemateca PortuguesaMuseu do Cinema IP e DGPC/ Museu Nacional de Etnologia. DVD legendado em inglês, $273 \mathrm{~min}$. pp 11-43.

COSTA, José Manuel. 2005. "Notas sobre a percepção do cinema como património cultural". Leituras: Revista da Biblioteca Nacional, 3 (1415):59-67.

COOPER, Frederick \& STOLER, Ann Laura. 1997. "Between metropole and colony: Rethinking a research agenda". In: F. Cooper \& A.L. Stoler (orgs.), Tensions of Empire: Colonial Cultures in a Bourgeois World. Berkeley: University of California Press. pp. 1-56.

CUNHA, Olívia Maria Gomes. 2004. "Tempo Imperfeito: Uma etnografia do arquivo", Mana, 10 (2):287-322. 2005. "Do Ponto de Vista de Quem? Diálogos, olhares e etnografias dos/nos arquivos", Estudos Históricos, 36:7-32.

CUSACK, Igor. 2005. "Tiny transmitters of nationalist and colonial ideology: The postage stamps of Portugal and its Empire". Nations and Nationalism, 11 (4):591-612.

DE KLERK, Nico. 2008a. "The Netherlands Archive/ Museum Institute". In: K.L. Ishizuka \& P.R. Zimmermann (orgs.), Mining the Home Movie: Excavations in histories and memories. Los Angeles and London: University of California Press. pp. 142-147.

2008b. "Home away from home: Private films from the Dutch-East Indie". In K.L. Ishizuka \& P.R. Zimmermann (orgs.), Mining the Home Movie: Excavations in histories and memories. Los Angeles and London: University of California Press. pp. 148-163. 
DEPREZ, Camille. 2014. "Colonial Discourse and Documentary Film at the Margins: The case of Delhi Grande Ville de l'Inde Supérieure and Dans l'État du Cachemire, two early Pathé Frères films shot in India". Studies in European Cinema, 11 (1):26-39.

DIAS, Nélia. 1991. Le Musée d'ethnographie du Trocadéro (18781908): Anthropologie et Museologie en France. Paris: Editions du CNRS. . 2014. "Rivet's Mission in Colonial Indochina (1931-1932) or the Failure to Create an Ethnographic Museum". History and Anthropology, 25 (2):189-207.

. 2015. "From French Indochina to Paris and back again: The circulation of objects, people and information, 1900-1932". Museum \& Society, 13 (1):7-21 .

DOMINGOS, Nuno. 2012. "Cultura Popular Urbana e Configurações Imperiais". In: M.B. Jerónimo (org.), O Império Colonial em Questão (sécs. XIX-XX): Poderes, saberes e instituições. Lisboa: Edições 70. pp. 391-421.

EDWARDS, Elizabeth. 2002. "Material Beings: Objecthood and ethnographic photographs". Visual Studies, 17 (1):67-75.

. 2012. "Objects of Affect: Photography beyond the image". Annual Review of Anthropology, 41:221-34.

EDWARDS, Elizabeth \& HART, Janice (orgs.) 2004a. Photographs Objects Histories: on the materiality of images. Londres e Nova Iorque: Routledge.

. 2004b. "Mixed Box: The cultural biography of a box of 'ethnographic' photographs". In: Elizabeth Edwards \& Janice Hart (orgs.), Photographs Objects Histories: On the materiality of images. Londres e Nova Iorque: Routledge. pp. 47-61.
ELSAESSER, Thomas. 2001. "Writing and rewriting film history: Terms of a debate". CINEMA \& Cie, 1:26-33. . 2016. Film History as Media Archaeology: Tracking Digital Cinema. Amsterdam: Amsterdam University Press.

FREHSE, Fraya. 2005. "Os informantes que jornais e fotografias revelam: para uma etnografia da civilidade nas ruas do passado", Estudos Históricos, 36:131-156.

GEARY, Christraud M. \& WEBB, Virginia-Lee (orgs.). 1998. Delivering Views: Distant cultures in early postcards. Washington, DC: Smithsonian Institution Press.

JEFFERY, Keith. 2006. "Crown, Communication and the Colonial Post: Stamps, the monarchy and the British empire". The Journal of Imperial and Commonwealth History, 34 (1):45-70.

KOPYTOFF, Igor. 1986. "The Cultural Biography of Things: Commoditization as process". In: Arjun Appadurai (org.), The Social Life of Things: Commodities in Cultural Perspective. Cambridge: Cambridge University Press. pp. 64-91.

KOTHARI, Uma. 2014. "Trade, consumption and development alliances: The historical legacy of the Empire Marketing Board poster campaign". Third World Quarterly, 35 (1):43-64.

LADWIG, Patrice; ROQUE, Ricardo; TAPPE, Oliver; KOHL, Christoph \& BASTOS, Cristiana. 2012. "Fieldwork between folders: Fragments, traces, and the ruins of colonial archives". Working Paper 141. Halle/ Salle: Max Planck Institute for Social Anthropology.

MACCABE, Colin. 2011. "'To take ship to India and see a naked man spearing fish in blue water': Watching Films to Mourn the End of Empire". In: L. Grieveson \& C. MacCabe (orgs.), 
Empire and Film. BFI/ Palgrave Macmillan. pp. 1-17.

MARTINS, Leonor Pires. 2012. Um império de papel. Imagens do colonialismo português na imprensa periódica ilustrada (1875-1940). Lisboa: Edições 70.

MATOS-CRUZ, José. 1989. Prontuário do Cinema Português, 1896-1989, Lisboa: Cinemateca Portuguesa.

MAXWELL, Anne. 1999. Colonial Photography and Exhibition: Representations of the 'Native' People and the Making of European Identities. London and New York: Leicester University Press.

MAYER, Ruth. 2002. Artificial Africas: Colonial Images in the Times of Globalization. Hanover e Londres: University Press of New England.

MITCHELL, W.J.T. 2002. "Showing Seeing: A critique of visual culture". Journal of Visual Culture, 1 (2):165-181.

MOYER, James F. 2007. "Film and the Public Memory: The phenomena of nonfiction film fragments". Contemporary Aesthetics, 7. Disponível em: http://www.contempaesthetics.org/ newvolume/pages/article.php?articleID $=482$. Acesso em 02/05/2018.

PIÇARRA, Maria do Carmo. 2015. Azuis Ultramarinos: Propaganda Colonial e Censura no Cinema do Estado Novo. Lisboa: Edições 70.

PIÇARRA, Maria do Carmo; CABECINHAS, Rosa \& CASTRO, Teresa. 2016. "Imaginários Coloniais: Propaganda, militância e 'resistência' no cinema". Comunicação e Sociedade, 29:9-15.

PIMENTEL, Joana. 2002. "La Collection coloniale de la Cinemateca Portuguesa-Museu do Cinema: 19081935". Journal of Film Preservation, 64:22-30.
PORTO, Nuno. 2001. "Picturing the Museum: Photography and the work of mediation in the Third Portuguese Empire". In: M. Bouquet (org.), Academic Anthropology and the Museum. Back to the Future. Oxford and New York: Berghahn. pp. 36-54. . 2004. "Under the Gaze of the Ancestors: Photographs and performance in colonial Angola". In: E. Edwards \& J. Hart (orgs.), Photographs Objects Histories: on the Materiality of Images. Londres e Nova Iorque: Routledge. pp. 113-131.

RAJ, Kapil. 2013. "Beyond Postcolonialism... and Postpositivism: Circulation and the global history of science". Isis, 104 (2):337-347.

RICE, Tim. 2011. "Exhibiting Africa: British Instructional Films and the Empire Series (1925-8)". In: Lee Grieveson \& Colin MacCabe (orgs.), Empire and Film. BFI/ Palgrave Macmillan, pp. 115-133.

RYAN, James R. 1998. Picturing Empire: Photography and the Visualization of the British Empire. Chicago: University of Chicago Press.

. 2014. "Introdução. Fotografia Colonial". In: F.L. Vicente (org.), O Império da Visão: Fotografia no contexto colonial (1860-1960). Lisboa: Edições 70.

SAMPAIO, Sofia. 2015. "Turismo, Olhares e Imagens em Movimento: Do arquivo como repositório ao arquivo como campo". Análise Social, 217, L (4) :830-843.

2016. "Jornal Português: Revista Mensal de Actualidades 1938-1951 (recensão crítica)". Análise Social, 219, LI (2):467-472.

(org.). 2017. Viagens, Olhares e Imagens: Portugal 1910-1980. Lisboa: Cinemateca Portuguesa.

SASSOON, Joanna. 2004. "Photographic materiality in the age of digital reproduction". In: E. Edwards \& J. 
Hart (orgs.), Photographs Objects Histories: On the Materiality of Images. Londres e Nova Iorque: Routledge. pp. 186-202.

SEABRA, Jorge. 2011. África nossa: O império colonial na ficção cinematográfica portuguesa (1945-1974). Coimbra: Imprensa da Universidade de Coimbra.

SHERMAN, Daniel J. 2004. "'Peoples Ethnographic': Objects, Museums, and the Colonial Inheritance of French Ethnology". French Historical Studies, 27 (3):669-703.

STOLER, Ann Laura. 2008. “Imperial Debris: Reflections on Ruins and Ruination". Cultural Anthropology, 23 (2):191-219.

. 2009. Along the Archival Grain:

Epistemic Anxieties and Colonial Common Sense. Princeton e Oxford: Princeton University Press.

. 2013. Imperial Debris: On Ruins and Ruination. Durham: Duke University Press.
THOMAS, Nicholas. 1994. Colonialism's Culture: Anthropology, travel and government. Cambridge: Polity Press. VARANDA, Jorge. 2007. "O biombo de fotos". In: P. Bernaschina (org.), Missão Botânica - Transnatural, Angola 1927-1937. Coimbra: Artez. pp. 7-41.

VICENTE, Filipa Lowndes. 2012. "Fotografia e Colonialismo: Para lá do visível". In: M.B. Jerónimo (org.), O Império Colonial em Questão (sécs. XIX-XX): Poderes, saberes e instituiÇões. Lisboa: Edições 70. pp. 423-453. (org.). 2014. O Império da Visão: Fotografia no contexto colonial (18601960). Lisboa: Edições 70.

WOODS, Philip. 2001. "From Shaw to Shantaram: The Film Advisory Board and the making of British propaganda films in India, 1940-1943". Historical Journal of Film, Radio and Television, 21 (3):293-308. 


\section{O QUE SOBROU: MATERIALIDADE E COLONIALISMO NUMA COLEÇÃO DE IMAGENS EM MOVIMENTO}

\section{Resumo}

Adotando uma abordagem antropológica e materialista das imagens em movimento e seus arquivos, o artigo analisa a chamada "coleção colonial" da Cinemateca Portuguesa-Museu do Cinema para refletir sobre o seu caráter fragmentário, as hesitações classificatórias que a atravessam e as implicações que poderá ter, dentro e fora do campo arquivístico. O objetivo do artigo é ir para lá das questões de representação, imaginário e propaganda que têm dominado o estudo das imagens coloniais, e questionar algumas ideias adquiridas, já que os fragmentos que sobraram da relação entre o cinema e as colônias portuguesas sugerem um projeto de dominação cauteloso, errático ou até indiferente em relação ao dispositivo cinematográfico. O artigo explora algumas das lições materiais do arquivo, sublinhando a necessidade de se complementarem futuros (e necessários) estudos empíricos com o aprofundamento dos avanços teóricos sugeridos.

Palavras-chave: Arquivo, Imagens em movimento, Materialidade, Colonialismo, Portugal (1908-75)

\section{WHAT REMAINED: MATERIALITY AND COLONIALISM IN A COLLECTION OF MOVING IMAGES}

\begin{abstract}
Adopting an anthropologically-informed materialist approach to moving images and their archives, the article analyses the so-called "colonial collection" of the Portuguese Film Museum. It reflects on its fragmentary condition, the classificatory hesitations that permeate it and the implications it may have, within and without the archival field. The aim is to move beyond issues of representation, imaginary and propaganda that have dominated the study of colonial images, and hence to question received ideas. What the fragments that have outlasted the relationship between cinema and the Portuguese colonies suggests is a project of domination that was cautious, erratic or even indifferent towards the cinematic apparatus. The article also explores some of the archive's material lessons, calling for the combination of much-needed empirical work with further theorization along the proposed lines.
\end{abstract}

Keywords: Archive, Moving images, Materiality, Colonialism, Portugal (190875) 


\section{LO QUE SOBRÓ: MATERIALIDAD Y COLONIALISMO EN UNA COLECCIÓN DE IMÁGENES EN MOVIMIENTO}

\section{Resumen}

Adoptando un enfoque antropológico y materialista de las imágenes en movimiento y sus archivos, el presente artículo analiza la llamada "colección colonial" de la Cinemateca PortuguesaMuseo del Cine para reflexionar sobre su carácter fragmentario, las dudas de clasificación que la atraviesan y las implicaciones que puede entrañar dentro y fuera del campo archivístico. El objetivo de este trabajo es ir más allá de las cuestiones de representación, imaginario y propaganda que han dominado el estudio de las imágenes coloniales, y cuestionar algunas ideas generalmente asumidas, ya que los fragmentos sobrantes de la relación entre el cine y las colonias portuguesas sugieren un proyecto de dominación cautelosa, errática o incluso indiferente en relación con el dispositivo cinematográfico. El artículo explora algunas de las lecciones materiales del archivo, subrayando la necesidad de complementar futuros (y necesarios) estudios empíricos con la profundización en los avances teóricos sugeridos.

Palabras clave: Archivo, Imágenes en movimiento, Materialidad, Colonialismo, Portugal (1908-1975) 